\title{
Measuring Selected M-Texting Addiction Indicators with Gender and Self-Esteem
}

\section{Nobukhosi Dlodlo}

\author{
Lecturer: Department of Marketing, Faculty of Management Sciences, Vaal University of Technology, \\ Private Bag X021, Vanderbijlpark, 1900 \\ Email: nobukhosid@vut.ac.za
}

\section{Doi:10.5901/mjss.2014.v5n23p489}

\section{Abstract}

The unprecedented level of both frustration and sensation-seeking behaviour among a majority of tertiary students has contributed to the mobile-device becoming a universal social destination for young people. Notwithstanding this fact, as the colossal explosion of mobile devices continues to proliferate, so do their abuses and various other problematic behaviours. Therefore, the primary purpose of this study was to identify the underlying M-texting addiction indicators that are pertinent among students within a South African university. The secondary purpose of this study was to investigate whether demographic and psychological attributes of individuals were related to M-texting addiction. A quantitative survey was conducted on a probability sample of 187 tertiary students. Exploratory factor analysis identified four M-texting addiction indicators. Reliability assessment using Cronbach alpha coefficients indicated adequate internal reliability and homogeneity among the scale items $(\alpha>0.70)$. From the study, it emerged that there was statistical and practical significance between the withdrawal, dependence and productivity loss dimensions with gender $(p<0.05)$. The results of this study indicate that mobile technology addictions remain paradoxical in that the victims use texting to become isolated, and this invariably leads to lower self-esteem. In relation to this, statistical and practical significance were established along the withdrawal and dependency dimensions $(p<0.05)$ when tested across the social self-esteem personality attribute. A clear understanding of M-texting addiction detection through educational intervention programmes can provide opportunities for designing new capabilities that will support healthy usage of mobile devices among students.

Keywords: mobile-device ; M-texting ; addiction ; gender ; self-esteem

\section{Introduction}

Mobile devices have transformed the way in which people communicate as well as how they synchronise their daily activities (Chak \& Leung, 2004). The mobile device has established itself technically, commercially, socially and in the imagination of the people. It has changed the way individuals think about communication, coordination and safety. The mobile telephone has become an element in our sense of public and private space and in the development of our social and psychological personas. A plethora of mobile devices have created opportunities for people to contact family and friends (Chen \& Katz, 2007), to relax (Chak \& Leung, 2004), to be involved in recreational activities, and further access and/or participate in social networking sites (Shambare, Rugimbana \& Zhowa, 2012).

Whilst mobile devices have been hailed for their intricate attributes such as portability and ubiquity (Hooper \& Zhou, 2007), personalisation and localisation (Bianchi \& Phillips, 2005), as well as ease of use (Young, 1996), both for individuals and businesses, have gained immense benefits from reliance on these technology advancements. However, numerous scholars (Chen \& Katz, 2007; Han \& Hur, 2004; Sánchez-Carbonell et al., 2008; Zulkefly \& Baharudin, 2009) have pointed out concerns with the excessive use of these devices for the purposes of texting.

The email statistics report indicated that the number of worldwide text messaging accounts in 2013 was approximately over 3.4 billion, with this figure expected to grow at an average annual rate of 7 percent, and reach 4.4 billion by year-end 2016 (Radicati, 2013). In addition, previous research has indicated that 75 percent of college students in the developed countries report that they use texting on any given day; this is twice as much as the average Internet user (Quan-Haase, 2008). Similarly, this trajectory has filtered down to the local frontier with much of the excitement in South Africa's electronics sector centred on mobile communications, which together with transport and storage, account for around 10 percent of the country's gross domestic product (GDP) output (Potgieter, 2014).

As of 2010, approximately 28 percent of the urban cellular market in South Africa was using mobile text messaging out of the 10.5 million potential users who have the applications installed on their mobile phones (Goldstuck, 2010). As such, the proliferation of mobile communication technologies has played a remarkable role in broadening the capacity of the communications sector in the country. Such podia have driven scholars to begin to question the social impacts of 
mobile messaging applications in people's lives (Lin, 2012). Text messaging has become an integral part of the lives of young people, as it is considered cheaper than voice calls in most developing countries (Lin, 2012). Potgieter (2014) opines that the levels of text dominance in the country, led by WhatsApp, which is being used by 79 percent of the student populace, followed closely by BlackBerry Messenger, at 57 percent while Apple's Imessenger and Mxit claimed 45 percent and 28 percent respectively, suggest that the problematic effects of M-texting usage among students cannot be underestimated.

In South Africa, available research has demonstrated individuals' subjective experiences with the technology and its application within educational contexts (Butgreit, 2007; Chigona \& Chigona, 2008; Dourando, Parker \& De la Harpe, 2007). However, the salience of mobile messenger applications in young people's daily lives has brought text messaging under scrutiny, particularly from the local media and other market analysts although much of the evidence is from nonscientific studies. It appears that there is a paucity of research, which questions the existence of behavioural addiction associated with excessive usage of M-texting among tertiary students. In addition, a significant amount of research has been created among the schoolchildren and teenage samples (Blair \& Fletcher, 2011; Huang \& Leung, 2009), although there is almost no research that seeks to create conversations about text messaging use among South African tertiary students (Chigona \& Chigona, 2008). Furthermore, even less is known about M-texting problematic behaviour among these users during their academic transition period at universities and colleges (Baron, 2004).

\subsection{M-texting addiction in context}

The concept of addiction reports on indications that suggest that some users were becoming addicted to the mobile phone in much the same way that others became addicted to drugs, alcohol, gambling or other related constituents. It follows then that the way to define addictive use of mobile devices clinically is to compare it against criteria for other established addictions. The American Psychiatric Association (1995) defines addiction as "any form of substance dependence" as measured by seven criteria as follows: (1) withdrawal from others in favour of the substance, (2) tolerance of the substance, (3) preoccupation with the substance, (4) heavier or more frequent use of the substance than intended, (5) deliberate intentions and activities to procure more of the substance, (6) loss of interest in other social, occupational, and recreational activities, and (7) disregard for the physical or psychological consequences caused by the use of the substance.

In the rapidly burgeoning literature in Internet technology research, seriously dysfunctional patterns of excessive technology use often are referred to as addiction or pathological use. Numerous reports have identified substantial rates of both addiction and pathological use of the mobile device for text messaging among adolescents and young adults in Asia (Cao \& Su, 2007; Huang \& Leung, 2009); America (Block, 2008; Jelenchick, Becker \& Moreno, 2012) and Europe (Bakken et al., 2008; Carbonelli et al., 2012; Milani, Osualdella \& Blasio, 2009). M-texting addiction will be used to describe this phenomenon, which can be operationalised by criterion that will be introduced in the next paragraphs.

Leung (2007) identified the main diagnostic criterion of mobile phone use as maladaptive patterns of activity leading to significant psychological impairment. This impairment is manifested by seven symptoms from a list of conditions including withdrawal, tolerance, pre-occupation with the substance, loss of control over the substance, more use of the substance than intended, continued consumption of the substance despite adverse consequences and loss of interest in other social, occupational and recreational activities (Huang \& Leung, 2009; Dourando et al., 2007). Other researchers have delimited M-texting addiction as using the device for an increasing amount of time in order to achieve satisfaction through messaging (Baron, 2004). In some cases of pathological use, unsuccessful efforts have been made to control, cut back, or stop cell phone use (Junco \& Cotten, 2011). The users end up feeling lost, restless, moody, depressed or irritable when attempting to cut down cell phone use. They text longer on the cell phone than originally intended; hiding from family and friends or others to conceal the extent of involvement with IM and using the text messaging service as a way of escape from problems or to evade loneliness (Lin, 2012). Therefore, in the absence of a universally accepted definition, any behaviour, which fulfils the aforementioned criteria, may be operationalised as Mtexting addiction.

\subsection{Gender and mobile-phone technology}

Historically, there appears to have been gender differences in relation to the uptake of new technology. Past research, for example, Ray, Sormunen and Harris (1999) established that men are more likely than women to hold positive attitudes towards computers are, and are thus more likely to embrace computer technology faster. Following on from this notion, logic would lead to the conclusion that males will be more likely than females to fall prey to problematic use of Internet- 
enabled mobile devices, as they are more likely to use computers more frequently, in the first instance. Some research has shown that this is indeed the case (Griffiths, 1998; Morahan-Martin \& Schumacher, 2000; Young, 1996). However, the research findings on technology and gender are not conclusive as existing gender differences may be a function of levels of socialisation, culture and access to technology within a specific society (Young, 1996). It is also possible that with time, any reported gender differences related to technology addiction, will cease to exist across the global student village. Given the inconsistencies in reported literature, it becomes difficult, therefore, to establish how this will translate into the addictive usage of mobile-devices for texting by both males and females within the context of university students that are based in South Africa.

\subsection{The psychology of self-esteem and M-texting addiction}

Rubin (2002) argued that individual life-position attributes such as personality or psychological health (inter alia leisure boredom, social self-esteem, loneliness and depression) will affect our motives to communicate, our strategies for seeking information and diversion, and our dependency on a particular technology medium.

Reeling from the latent trauma experienced in the pre-1994 apartheid era, a majority of South African youths are raised in homes suffering from severe woundedness. Several traits that include an inability to communicate on an emotional and human level, a tendency towards aggression, apathy and a sense of isolation forms a greater part of the ensuing intergenerational trauma, which they and their parents have experienced. The effects of this paradoxical woundedness have often translated into delinquent behaviour that characterises the ferocious responses of tertiary students to issues and/or challenges. Other effects of this political fallacy have been aligned to low self-esteem that is linked to mobile-device related problematic use among students.

Self-esteem is the evaluation and judgment of the worth of a person that one determines and maintains of him or herself (Leung, 2007). This construct is bound up with an individual's self-views of his/her identity of which these views are sustained by the social relationships that are created on mobile device platforms. Woo (2007) and Ehrenberg et al. (2008) report that people who hold negative evaluations about themselves use addictive substances to escape or withdraw from their low self-conceptions. Baumeister (1997) theorises that low self-esteem may cause people to behave in ways that are self-defeating in order to escape self-awareness. Therefore, various M-texting may be used as a form of escape from situations that the user finds aversive (AydÕna \& SarÕ, 2011). In addition, previous studies have demonstrated that low self-esteem is related to addictive behaviour (Niemz, Griffiths \& Banyard, 2005; Young, 1996). If people have a low opinion about themselves, and find it difficult to socialise because of their shyness or lack of selfesteem, they may use their personalised devices as an alternative form of socialising, in which they can open up and gain confidence without having to interact face-to-face.

\section{Motivation for the Study}

In South Africa, approximately, 68 percent of students connect to the Internet through smartphones, 61 percent via laptops or notebook computers and 20 percent on ipads/tablets. The trend is driven by some institutions providing a plethora of mobile devices to students coupled with low-cost financing of technological devices by student financial services like Eduloan. Relatedly, the unprecedented level of frustrations and sensation-seeking behaviour among a majority of tertiary students has contributed to the mobile-device becoming a universal social destination for young people. Notwithstanding this fact, as the inevitable explosion of mobile devices continues to proliferate, so do their abuses. This study was established and centred upon the people directly involved with a modern syndrome termed the twenty-first century non-drug addiction (Shambare et al., 2012).

Traditionally, the concept of addiction was maintained as a medical model based on excessive biological and emotional dependence upon a physical substance. However, more recent research (Chóliz, Villanueva \& Chóliz 2009; AydÕna \& SarÕ, 2011; Chak \& Leung, 2004) has incorporated various technological forms of addiction, which are nonchemical in nature; better described as human-device interactive addiction (Griffiths, 1998). Therefore, to be able to contribute to addiction research literature in South Africa, this research aimed to unravel the underlying indicators and symptoms of M-texting addiction among university students. To date there has been little description of the ways that young people are engaging in excessive usage of mobile technologies. Similarly, the linkages between m-addictive tendencies with gender and self-esteem have been explored scantly. Problematic use of M-texting among the student community, therefore, remains a colossal challenge for educational psychologists and social scientists, and hence a study merited the author's attention. Therefore, to achieve the research objectives, the following research questions were formulated: 
RQ1: What are the underlying indicators of M-texting addiction among university students?

$R Q 2:$ Is there a significant difference between M-texting addiction dimensions with gender?

$R Q 3:$ Is there a significant difference between M-texting addiction dimensions with self-esteem?

\section{Research Methodology}

A quantitative, descriptive survey research design was followed in the study. The participants were self-selected using convenience sampling. A self-administered survey was utilised to collect the data.

\subsection{Participants}

Three hundred questionnaires were distributed to randomly selected participants recruited from several programmes within the management science faculty at the Vaal University of Technology. The sample size was consistent with previous addiction studies (Bianchi \& Phillips, 2005; Woo, 2007; Young, 2004). Of these, 214 were returned, giving a response rate of 80.3 percent. However, only 187 questionnaires were considered usable while the rest (27 responses) were discarded due to missing values. The study comprised of 51 percent female respondents $(n=96)$ while 49 percent of the sample were males ( $n=91)$. Ages ranged from 18 to 28 years (Mean=20.77; $S D=1.66)$. Approximately 63 percent of the sample $(n=118)$ were respondents of African background while the rest of the sample comprised whites $(24 \% ; n=45)$, Indians ( $8 \% ; n=15)$ and coloured (5\%; $n=9)$ respondents. This demographic representation was determined largely by the location of the survey site. Based on the self-reported findings of the respondents; 25 percent $(n=47)$ were classified as moderate users; 37 percent $(n=69)$ heavy users and 38 percent $(n=71)$ addicted users. Popular devices among the respondents were smartphones (67\%; $n=125)$; notebooks $(21 \% ; n=39)$ and tablets $(7 \% ; n=13)$. All of the participants conceded that they own and use an Internet-enabled mobile device regularly.

\subsection{Materials and methods}

In the absence of a comprehensive M-texting addiction scale, the author utilised the 30-item mobile phone problem usage scale (MPPUS) that was validated as a reliable self-report by Bianchi and Phillips (2005). The MPPUS scale was derived from the MMPI-2 addiction potential scale that was developed originally for assessing personality characteristics and lifestyle patterns that are associated with drug and alcohol abuse. In addition, the items on the questionnaire were aligned to the instrument developed by Hooper and Zhou (2007), which was specifically aimed at the student population group and would, therefore, be comprehensible to the target respondents.

On the other hand, the Rosenberg self-esteem scale consisting of ten items anchored on a seven-point Likert scale was used to provide an overall evaluation of one's worth or value. It is a brief measure with high test-retest internal reliability and validity ranging between 0.80 and 0.84 (Kivimaki \& Kalimo, 1996). In the current study, the Cronbach alpha for this scale was set at 0.812 . The original Rosenberg scale has been used to classify individuals into either the low social self-esteem (10-39) or high social self-esteem cohorts (40-70). Items on this scale included 'I feel that I have a number of good qualities', 'I certainly feel useless at times' and 'I am able to do things as well as most other people'. Both sections were anchored on a seven-point Likert scale with values ranging from strongly disagree (1) to strongly agree (7). The Likert scale was used, as it is relatively easy to construct, makes data easy to collect and analyse, thereby making them suitable for surveys (Kothari, 2008). The third section comprised of the demographic profile of the students, measuring different personal attributes of the respondents such as gender, age, ethnic group, tertiary education level and frequency of M-texting usage. These questions were structured on a dichotomous, multiple choice and ranking-order closed-ended scales.

\subsection{Reliability and validity of the study}

The reliability assessment for the M-texting addiction instrument was ascertained by computing Cronbach alpha coefficient values as shown on Table 1. According to Nunally (1978), Cronbach alpha coefficients of less than 0.50 are deemed unacceptable; those between 0.50 and 0.69 are considered as being adequate, whereas those above 0.70 are regarded as being acceptable. The sub-scale reliability values ranged between 0.802 and 0.891 indicating that the items were homogenous; while the standardised Cronbach alpha value for the entire scale was established at 0.867 indicating a satisfactory indication of internal consistency among the scale items. Therefore, these results corroborate the sufficiency of the scale as being adequate in capturing the elements included as the M-texting addiction determinants 
amongst South African university students.

Table 1. Cronbach alpha (a) values for the M-texting addiction dimensions

\begin{tabular}{llcc}
\hline Dimension/Construct & N & Number of items & Cronbach alpha \\
\hline Withdrawal & 187 & 6 & .891 \\
Compulsion & 187 & 6 & .810 \\
Dependence & 187 & 6 & .847 \\
Productivity loss & 187 & 5 & .802 \\
\hline Overall Cronbach alpha for the entire scale $=\mathbf{0 . 8 6 7}$ & & \\
\hline
\end{tabular}

\section{Findings and Discussion}

RQ1: What are the underlying indicators of M-texting addiction among students at the Vaal University of Technology?

The underlying indicators of M-texting addiction were determined using exploratory factor analysis (EFA) with a view to identify a set of latent (hidden) constructs underlying a battery of measured variables (Norris \& Lecavalier 2009). Similarly, the aim of applying a common factor route was to reveal any latent variables that cause the manifest variables to co-vary with a view to condensing those experimental variables into identifiable constructs. Initially, two tests were performed with a view to examine the appropriateness of the data set for conducting EFA. First, the Bartlett's test of sphericity was significant at $p<0.000$ inferring that the data set was not an identity matrix with zero correlations. Secondly, the test revealed a chi square value $\left(X^{2}\right)$ of 3753.686 . Thirdly, the KMO measure of sampling adequacy was established at a value of of $0.894(>0.50)$.

Principal component analysis (PCA) was performed as the default factor extraction method, while the rotation method was the Varimax method converged in six iterations. Selection of this orthogonal rotation method with Kaiser normalisation was aimed at producing factors that are uncorrelated, leading to high factor interpretability.

Both over-extraction and under-extraction of factors retained for rotation can have deleterious effects on the results. Therefore, item reduction and scale purification were conducted through an examination of the items with low factor loadings, communalities and low-item-to-total correlations with a view to enhance "interpretability of the factor structure" (Malhotra, 2010:643). A minimum cut-off of 0.50 was used on the variable loadings. This is consistent with Hair et al. (2010) who suggested that factor loadings greater than \pm 0.30 are considered to meet the minimum levels, loadings of \pm 0.40 are considered important while loading of \pm 0.50 and greater are considered more important. A threshold of 0.4 to 0.70 was maintained on the communalities as well as a cut-off point of 0.30 on the item-to-total correlations, as guided by Kim and Mueller (1978). Resultantly, seven items were eliminated after the refinement procedure, suggesting that those items may be incapable of differentiating between factors.

In the factor extraction procedure, the default measure used in this study (as in most statistical software packages) was to use Kaiser's (1956) eigenvalues greater than one criteria, whose total variance contribution is considered significant (Zikmund \& Babin, 2007). In addition, the percentage of variance explained and the scree plot criterion guided the extraction of factors. The Statistical Package for Social Sciences (SPSS) data output (version 21.0) revealed a clear four-factor structure condensed over 23 items. The total variance explained by the extracted factors was 71.5 percent, indicating that the other 28.5 percent is accounted for by extraneous variables that do not constitute part of this study (non-addiction related variables). The factors were labelled withdrawal, compulsion, dependence and productivity loss. 
Table 2: Rotated factor loadings and psychometric evaluation of the scale

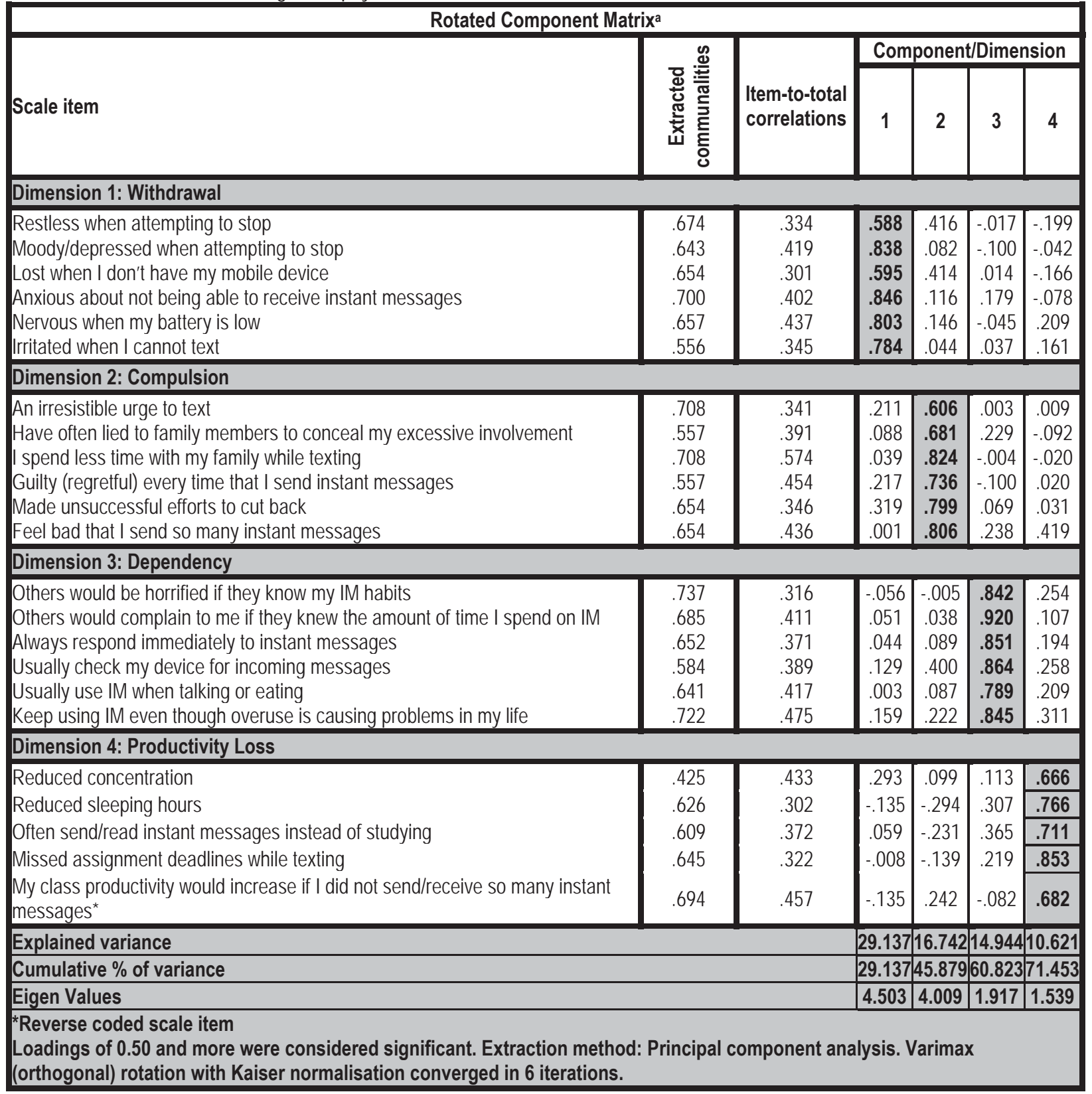

The first factor explained 29.1 percent of the total post-rotation variance with an eigenvalue of 4.503 . The six items that make up this factor show that there are various psychological and temperamental changes that may be observed among students with M-texting addiction problems. Students reported that they feel lost when they do not have their mobile phone and feel restless, moody, depressed and/or irritable when the mobile device is not available i.e. when the battery died or when there are network challenges. Mood swings and relapses during the period of involuntary abstinence are also common. This factor was labelled 'withdrawal', which refers to the feelings and symptoms of panic, anxiety, agitation or other negative affect when the activity an individual was engaged in is inhibited (LaRose, Lin \& Eastin, 2003; Han \& Hur, 2004). Woo (2007) affirmed that this is common conduct, especially among students who tend to show withdrawal symptoms such as feeling lost in the absence of their source of contact comfort. Therefore, it may be argued that the excessive usage of mobile devices for texting purposes is a non-chemical and modern day addiction, which poses acute withdrawal symptoms among various individuals.

The second factor, compulsion (eigenvalue $=4.009$ ), explained 16.7 percent of the total post-rotation variance. The six items that make up this factor reveal that students had continuously made unsuccessful efforts to cut back on their 
excessive usage of mobile devices for texting purposes. However, the irritating urge to engage with their devices had often led them to persist, uncontrollably with the addictive tendency of texting regardless of the negative consequences of such related behaviour such as lying to friends and family.

The third factor, dependency (eigenvalue $=1.917$ ) explained 14.9 percent of the total post-rotation variance. The six items that make up this factor reveal that the respondents exhibited signs of pathological usage of M-texting. The students conceded that they increasingly are pre-occupied with texting on their mobile devices, even while eating or talking to others. The students further asserted that others would be horrified if they knew about their obsessive conduct and amount of time spent while texting on mobile devices. Contrary to findings of Hooper and Zhou (2007), this study demonstrates that the emotional attachment to a specific social norm may be a direct indicator of an individual's addictive tendencies. This is because the respondents usually take longer checking or responding to calls or chat messages on their devices, such that they find it difficult to discontinue usage when required to do so.

The fourth factor, productivity loss (eigenvalue $=1.539$ ), explained 10.6 percent of the total post-rotation variance. The five items that make up this factor reveal astounding general life disturbances that are inevitable among addicted Mtexting users. Indicators of addiction were identified as reduced concentration and sleeping hours due to this problem. Their academic work and general lifestyle patterns are sometimes disturbed by text messaging and online chats to an extent that they even seem to undergo some illusions whilst not using the mobile devices (Junco \& Cotten, 2011). Shambare et al. (2012) also reported the association between increased M-texting usage and specific health compromising behaviour such as reduced sleeping hours, compromised concentration levels, poorer attention capacity, reduced educational aspirations and exhaustion.

\subsection{Correlation analysis: M-texting addiction dimensions}

In order to examine the relationship among the M-texting addiction dimensions, Pearson's parametric correlation test statistic $(r)$ was computed. This correlation test statistic is used to describe the existence of a relationship amongst the constructs as well as the strength and direction of the association. The aim was to demonstrate the level of cohesiveness among the four dimensions identified in the study with a view to perform further statistical analysis on the data set. The results are reported on Table 3.

The inter-factor correlations revealed moderate to strong associations among the dimensions. Withdrawal showed strong, significant and positive correlations with compulsion $(r=0.685 ; p<0.01)$; dependence $(r=0.433 ; p<0.05)$ and productivity loss $(r=0.583 ; p<0.01)$. However, moderate, significant correlation coefficients were established on the dependence $(r=0.496 ; p<0.05)$ and productivity loss dimensions $(r=0.443 ; p<0.05)$ when correlated with the compulsion factor. Similarly, dependence $(r=0.437 ; p<0.05)$ demonstrated strong, significant and positive associative power with productivity loss. Therefore, all $r$-values for all research constructs were above the recommended 0.40 , indicating acceptable inter-factor convergent validity as more than 50 percent of each factor's variance was shared with its respective construct (Zikmund \& Babin, 2007).

Table 3. Inter-factor correlations (M-texting addiction dimensions)

\begin{tabular}{|l|c|c|c|c|}
\hline Construct & Withdrawal & Compulsion & Dependence & Productivity loss duty \\
\hline Withdrawal & 1 & $.685^{* *}$ & $.433^{*}$ & $.583^{* *}$ \\
\hline Compulsion & & 1 & $.496^{*}$ & $.443^{*}$ \\
\hline Dependence & & 1 & $.437^{*}$ \\
\hline Productivity loss & & & & 1 \\
\hline${ }^{* *}$ Correlation is significant at the 0.01 level. * Correlation is significant at the 0.05 level (2-tailed) \\
\hline
\end{tabular}

RQ2: Is there a significant difference between M-texting addiction dimensions with gender?

Independent t-tests were computed in order to explore the possible existence of any gender-based differences along the identified M-texting addiction dimensions as reported on table 4. Furthermore, to make qualitative judgements for assessing the effect size of the correlation coefficients; practical significance was computed using Cohen's d-statistic. The following guideline, as suggested by Cohen (1988), was used to measure effect sizes:

- $\mathrm{d}=.10$ to .29 (small effect)

- $\mathrm{d}=.30$ to .49 (medium effect)

- $\mathrm{d}=.50$ and greater (large effect) 
Table 4: Test for differences between means: M-texting addiction dimensions with gender

\begin{tabular}{|l|c|c|c|c|c|c|c|c|c|}
\hline \multirow{2}{*}{ Dimension } & \multicolumn{2}{|c|}{ Cohen's d statistic } & \multicolumn{2}{|c|}{ Males (n=91) } & \multicolumn{2}{c|}{ Females (n=96) } & \multicolumn{3}{c|}{ Test for Differences } \\
\cline { 2 - 10 } & $\mathrm{d}$ & Effect size & Mean & SD & Mean & SD & F & $\boldsymbol{t}$ & $\mathbf{p}$-value \\
\hline Withdrawal & .576 & Large & 4.187 & .784 & 5.551 & .791 & 1.382 & 2.549 & $.000^{\star \star}$ \\
\hline Compulsion & .091 & None & 3.519 & .849 & 3.523 & .805 & .798 & .876 & .651 \\
\hline Dependence & .201 & Small & 5.654 & .618 & 4.958 & .766 & 1.416 & 2.009 & $.026^{\star}$ \\
\hline Neglect of duty & .443 & Medium & 5.997 & .781 & 4.815 & .689 & 1.528 & 3.651 & $.041^{\star}$ \\
\hline
\end{tabular}

The results of the independent sample t-tests revealed that there were positive and statistically significant differences regarding the withdrawal dimension $(F=1.382 ; t=2.549 ; p<0.01)$ between male and female participants. Female users seem to demonstrate higher M-texting withdrawal symptoms ( $\bar{x}=5.551 ; \mathrm{SD}=.791)$ compared to their male counterparts ( $\bar{x}=4.187$; SD=.784). In addition, withdrawal yielded a large effect size $(\mathrm{d}=0.576)$ indicating the practical significance of this dimension in predicting M-texting addiction.

While no statistical $(F=.798 ; t=.876 ; p>0.05)$ nor practical significance $(d=0.091)$ was observed along the compulsion dimension, the results of this study indicate that both male $(\bar{x}=3.519 ; \mathrm{SD}=.849)$ and female $(\bar{x}=3.523$; $\mathrm{SD}=.805$ ) users of M-texting exhibit similar tendencies regarding their M-texting control disorder. This means that both male and female respondents reported similar results regarding the M-texting behaviour that is repetitive whereby the concerned individual usually experiences a strong urge to use their mobile device for texting purposes continuously. This is consistent with findings of Young (1998) and Swanepoel and Thomas (2012), who found no schooling-level or genderbased differences among a group of American $(N=496)$ and South African $(N=152)$ respondents, respectively.

Furthermore, the study revealed positive and statistically significant differences regarding the productivity loss dimension ( $F=1.528 ; t=3.651 ; p<0.05)$ between male and female participants. Male users seem to demonstrate a weakness regarding maintaining focus and productivity on their academic engagements ( $\bar{x}=5.997$; SD $=.781$ ) compared to their female counterparts ( $\bar{x}=4.815 ; \mathrm{SD}=.689)$ as a result of excessive use of M-texting. In addition, this dimension yielded a medium effect size $(\mathrm{d}=0.443)$ indicating the practical significance of this dimension in predicting overall $\mathrm{M}$ texting addiction across a gender-based sample group. The literature has reported on negative correlations between addiction tendencies with academic outcomes including poor grades, tardiness and procrastination (Neo \& Skoric, 2009; Schwarz, 2011). However, the gender-based variations along this factor remain inconclusive in extant literature (Bianchi \& Phillips, 2005). The research conducted by Morgan and Cotten (2003) showed that males pay more attention to Mtexting and to schoolwork at the same time, leading to reduced capacity for essential processing and representational holding. In turn, this will increase the student's cognitive demands suggesting that the learner has less cognitive resources to engage in the essential processing necessary to focus on information and in turn, to engage in deep, meaningful learning (Junco \& Cotten, 2011).

In terms of the dependence dimension, significant differences were noted $(F=1.416 ; t=2.009 ; p<0.05)$ among male and female participants. Furthermore, male participants showed a significantly higher mean value $(\bar{x}=5.654$; SD $=.618$ ) compared with their female counterparts ( $\bar{x}=4.958 ; \mathrm{SD}=.766$ ). In addition, dependence yielded a small effect size $(d=0.201)$ indicating the practical significance of this dimension in predicting overall M-texting addiction among male and female users. Aoki and Downes (2003) stated that as participants start using mobile phones regularly, texting becomes part of their lives and they feel lost without it. These findings are supported by studies of Blair and Fletcher (2011) who argued that dependency is synonymous with commitment to using a technology, of which such commitment enables the adopter to begin using their mobile device regularly to their own personal detriment. Hooper and Zhou (2007) further affirmed that that M-texting provides a privileged place for males to indulge in narcissistic pleasures that allow for privacy as well as self-introspection.

RQ3: Is there a significant difference between M-texting addiction dimensions with self-esteem

\subsection{Self-esteem scoring}

Based on the severity of addictive behaviour among youths (Flanagin, 2005) and the corresponding impact on pathological use and personality disorders, particularly within a South African context (Swanepoel \& Thomas, 2012), the self-esteem score was dichotomised into a binary variable coded as (1) low self-esteem ( $40 \leq$ score $\leq 69)$ and (2) high selfesteem $(70 \leq$ score $\leq 100)$. From the sample data, a majority of participants $(56 \% n=105)$ were categorised as having high social self-esteem while the remaining participants $(44 \% n=82)$ were classified as having low self-esteem. 
Table 5. Test for differences between means: M-texting addiction dimensions with self-esteem

\begin{tabular}{|l|c|c|c|c|c|c|c|c|c|}
\hline \multirow{2}{*}{ Dimension } & \multicolumn{2}{|c|}{ Cohen's D' statistic } & \multicolumn{2}{c|}{ High Self-Esteem $(\mathbf{n}=105)$} & \multicolumn{2}{c|}{ Low Self- Esteem $(\mathbf{n}=\mathbf{8 2})$} & \multicolumn{2}{c|}{ Test for Differences } \\
\cline { 2 - 9 } & $\boldsymbol{d}$ & Effect size & Mean & SD & Mean & SD & $\mathbf{F}$ & $\boldsymbol{t}$ & $\boldsymbol{p}$-value \\
\hline Withdrawal & .319 & Medium & 3.614 & 1.184 & 5.978 & 1.034 & 2.344 & 2.102 & $.044^{*}$ \\
\hline Compulsion & .016 & None & 3.509 & 0.543 & 3.591 & 0.938 & 5.092 & 1.961 & .826 \\
\hline Dependency & .622 & Large & 3.804 & 1.922 & 5.269 & .895 & .160 & 2.425 & $.008^{\star *}$ \\
\hline Neglect of duty & .043 & None & 5.221 & .916 & 5.217 & .831 & 4.251 & 1.377 & .572 \\
\hline
\end{tabular}

Regarding the withdrawal dimension, statistically significant differences were noted $(F=2.344 ; t=2.102 ; p<0.05)$ with social self-esteem. The participants with lower self-esteem demonstrated a significantly higher mean value $(\bar{x}=5.978$; $\mathrm{SD}=1.034)$ compared with their counterparts who had higher self-esteem scoring ( $\bar{x}=3.614 ; \mathrm{SD}=1.184)$. In addition, the withdrawal dimension yielded a medium effect size $(d=0.319)$ indicating the practical significance of this dimension in predicting overall M-texting addiction among users with varying levels of self-esteem. This suggests that confident people with a high self-esteem generally enjoy a large social circle, but they only spend a short time texting on their mobile devices, just sufficient to achieve their ends. These findings are supported by studies of Leung (2007) who postulated that Subjects who score low on self-esteem will report a higher amount of mobile phone feature use as well as increased incidences of M-texting.

Furthermore, the results of the independent sample t-tests revealed that there were positive and statistically significant differences regarding the dependency dimension ( $F=.160 ; t=2.425 ; p<0.01)$ with self-esteem. M-texting users with low self-esteem seem to demonstrate higher symptoms of M-texting dependency $(\bar{x}=5.269 ; \mathrm{SD}=.895$ ) compared to users with high self-esteem $(\bar{x}=3.804 ; \mathrm{SD}=1.922)$. In addition, dependency yielded a large effect size $(d=0.622)$ indicating the practical significance of this dimension in predicting M-texting addiction among users with varying levels of self-esteem.

No statistical significance was observed along the compulsion dimension $(F=5.092 ; t=1.961 ; p>0.05)$ and on the productivity loss factor $(F=4.251 ; t=1.377 ; p>0.05)$ with self-esteem. In addition, the absence of practical significance was reported along both compulsion ( $d=.016)$ and productivity loss $(d=.043)$ indicating that social self-esteem does not necessarily determine the extent to which students will be compulsive or disturbed in their academic duties as a result of M-texting. These results may be explored further in future studies.

\section{Limitations, Implications and Further Research}

The findings of the study constitute an important source of knowledge and information on issues pertaining to a relatively unfamiliar phenomenon, M-texting addiction. It should be noted that while the measuring scale, which was used in this study provides a workable measure of technology-based addiction, further study is needed to determine its construct validity and clinical utility. However, the study has a limitation in that its results are restricted to one university located in only one province in South Africa and the responses from only 187 participants were utilised in the study. This implies that caution must be exercised when generalising the results to other geographical locations and contexts.

In keeping with the growing body of the literature related to the physical, financial and social implications of problematic technological use, this research may serve as a first-step, indicator for continued studies and interventions by clinicians and policy makers when addressing the factors that may be important when dealing with M-texting addiction tendencies. It is noteworthy to mention that this research did not intend to create an exposé of behaviour that could indeed be classified as a bad habit, but rather aimed to unravel the potential negative consequences of excessive usage of M-texting and such related psychological indicators among users. Therefore, several recommendations may be posed in light of this setting. Disclaimers may be presented on various mobile device menu pages, highlighting the dangers of excessive usage of mobile technologies that could futilely lead to M-texting addiction. Another strategy could be progressively to shift problem users to devices with less intrusive features. A clear understanding of addiction detection through educational intervention programmes can provide opportunities for designing new capabilities that will support healthy usage of mobile devices among students. However, there is a need to internationalise this scholarship in a manner that pinpoints similarities and differences between South African and non-African university students in terms of their behavioural actions, motivations and needs related to technological addictions.

\section{Conclusions}

Mobile technological developments result in a dizzying change in the world, leaving an immense impression on countries, 
communities and individuals per se. As a result, the social, economic, political and cultural impasse posed by such modern developments has become a relevant subject for discussion. Four reliable factors were identified in this study as the underlying M-texting addiction indicators, namely; withdrawal, compulsion, dependency and productivity loss. A quantitative, descriptive survey research design was conducted on a sample of 187 university students. Statistical and practical significance was observed between the withdrawal, dependency and productivity loss dimensions with gender. In addition, students who scored low results on the self-esteem scale essentially reported an inclination towards dependency and withdrawal patterns resulting from the uncontainable usage of M-texting. The findings of this research contribute to the nascent literature on the relationships between mobile communication technology usage and personality disorientation. However, the available measures of technology usage are rather limited. Ideally, studies of this type should examine a variety of types, amounts and timing of technology usage to determine their impacts on human personality traits. Second, longitudinal addiction studies are needed that follow students over time from high school through university to ascertain the causal processes involved in these relationships.

\section{References}

American Psychiatric Association. (1995). Diagnostic and statistical manual of mental disorders. (4th ed.). Washington, DC.

Aoki, K., \& Downes, E. J. (2003). An analysis of young people's use of and attitudes toward cell phones. Telematics and Informatics, 20(4), 349-364.

AydÕna, B., \& SarÕ, S. V. (2011). Internet addiction among adolescents: the role of self-esteem. Procedia Social and Behavioral Sciences, 15(1), 3500-3505.

Bakken, I. J., Wenzel, H. G., Gotestam, K. G., Johansson, A., \& Oren, A. (2009). Internet addiction among Norwegian adults: a stratified probability sample study. Scandinavian Journal of Psychology, 50(2), 121-127.

Baron, N. S. (2004). See you online: gender issues in college student use of instant messaging. Journal of Language and Social Psychology, 23(1), 397-423.

Bianchi, A., \& Phillips, J.G. (2005). Psychological predictors of problem mobile phone use. Cyber Psychology and Behavior, 8(1), 39-51.

Baumeister, R. F. (1997). Esteem threat, self-regulatory breakdown, and emotional distress as factors in self-defeating behaviour. Review of General Psychology, 1(2), 145-174.

Blair, B., \& Fletcher, A. (2011). The only 13 year old on planet earth without a cell-phone: meanings of cell-phones in adolescents' everyday lives. Journal of Adolescence Research, 26(1), 155-177.

Block, J. J. (2008). Issues for DSM-V: Internet addiction. American Journal of Psychiatry, 165, 306-307.

Butgreit, L. (2007). Math on MXit: using MXit as a medium for mathematics education. Meraka Innovate Conference for Educators, CSIR, Pretoria, (18-20 April). South Africa.

Cao, F., \& Su, L. (2007). Internet addiction among Chinese adolescents: prevalence and psychological features. Child Care Health Development, 33(3), 275-281.

Carbonelli, X., Chamarro, A., Griffiths, M., Oberst, U., Cladellas, R., \& Talarn, A. (2012). Problematic Internet and cell phone use in Spanish teenagers and young students. Anales de psicología, 28(3), 789-796.

Chak, K., \& Leung, L. (2004). Shyness and locus of control as predictors of Internet addiction and Internet use. Cyber Psychology and Behaviour, 7(5), 559-570.

Chen, Y., \& Katz, J.E (2007). Extending family to school life: College students' use of mobile phone. Paper presented at the annual International Communication Association. [Online] Available: http://www.allacademic.com/meta/p171018. html. (Accessed 12 June 2014).

Chigona, A., \& Chigona, W. (2008). MXit it up in the media. Media discourse analysis on a mobile instant messaging system. The Southern African Journal of information and Communication, 9, $42-57$.

Chóliz, M. Villanueva, V., \& Chóliz, M. C. (2009). Ellos, ellas y su móvil: Uso, abuso (¿y dependencia?) del teléfono móvil en la adolescencia. Re-vista Española de Drogodependencias, 34(1), 74-88.

Cohen, J. (1988). Statistical power analysis for the behavioral sciences (2nd ed.). Hillsdale, NJ: Lawrence Earlbaum Associates.

Dourando, D., Parker, M., \& De la Harpe, R. (2007). Investigation into the usage of mobile instant messaging in tertiary education. In proceedings of the 9th annual conference on World Wide Web applications 5-7 September 2007, Johannesburg, South Africa. [Online] Available: http://staging.uj.ac.za/www2007/documents/proceedings/Dourando_Parker_DelaHarpe_Investigation_ usage_of_mobile_messaging.pdf. (Accessed 18 May 2014).

Ehrenberg, A. S. Juckes., White, K. M. \& Walsh, S. P. (2008). Personality and self-esteem as predictors of young people's technology use. CyberPsychology and Behavior, 11(6), 739-741.

Flanagin, A. J. (2005) IM online: instant messaging use among college students. Communication Research Reports, 22(3), 175-187.

Griffiths, M. D. (1998). Internet addiction: does it really exist? In J. Gackenbach, J. (Ed.), Psychology and the Internet: intrapersonal, interpersonal and transpersonal applications (pp. 61-75). New York: Academic Press.

Goldstuck, M. (2010). Messaging drives SA mobile Internet. [Online] Available: www.southafrica.info/business/trends/newbusiness/ mobileinternet-270510.htm\#.u808ovbvmk. (Accessed 12 June 2014).

Hair, J. F., William, C. B., Babin, B. J., \& Anderson, R. E. (2010). Multivariate data analysis. Englewood Cliffs, NJ: Prentice Hall.

Han, J.L., \& Hur, G.H. (2004). Construction and validation of mobile phone addiction scale. Korean Journal of Journalism and Communication 
Studies, 48(1), 138-165.

Hooper, V., \& Zhou, Y. (2007). Addictive, dependent, compulsive? A study of mobile phone usage. Conference Proceedings of the 20th Bled eConference e-Mergence: Merging and Emerging Technologies, Processes, and Institutions held in Bled, Slovenia, June 4-6.

Huang, H., \& Leung, L. (2009). Instant messaging addiction among teenagers in China: shyness, alienation, and academic performance. Cyberpsychology and Behavior, 12(6), 675-679.

Jelenchick, L. A., Becker, T., \& Moreno, M. A. (2012). Assessing the psychometric properties of the Internet addiction test (IAT) in US college students. Psychiatry Research, 196, 296-301.

Junco, R., \& Cotten, S. R. (2011). Perceived academic effects of instant messaging use. Computers and Education, 56 (1), $370-378$.

Kaiser, H. F. (1956). A second generation little jiffy. Psychometrika, 35, 401-415.

Kim, J. O., \& Mueller, C.W. (1978). Factor analysis: statistical methods and practical issues. Beverly Hills, CA: Sage.

Kivimaki, M. \& Kalimo, R. (1996). Self-esteem and the occupational stress process testing two alternative models in a sample of blue-collar workers. Journal of Occupational Health Psychology, 1, 187-196.

Kothari, C.R. (2008). Research methodology: methods and techniques. (2nd ed.). New Delhi: New Age International.

LaRose, R., Lin, C. A., \& Eastin, M. S. (2003). Unregulated internet usage: addiction, habit, or deficient self-regulation? Media Psychology, 5(3), 225-253.

Leung, L. (2007). Leisure boredom, sensation seeking, self-esteem, addiction symptoms and patterns of cell phone use. In E.A. Konijn, M. A. Tanis, S. Utz \& A. Linden. (Eds.), Mediated interpersonal communication, (pp. 359-381). USA: Lawrence Erlbaum Associates.

Lin, S. (2012). Instant messaging on interpersonal relationship: How it brings intimacy and negative feelings? Masters Project. School of Journalism and Communication. Hong Kong: The Chinese University of Hong Kong.

Malhotra, N. K. (2010). Marketing research: an applied orientation. Eaglewood Cliffs: Prentice-Hall.

Milani, L., Osualdella, D., \& Di Blasio, P. (2009). Quality of interpersonal relationships and problematic Internet use in adolescence. Cyberpsychology and Behavior, 12, 681-684.

Morahan-Martin, J., \& Schumacher, P. (2000). Incidence and correlates of pathological internet use among college students. Computers in Human Behavior, 16, 13-29.

Morgan, C., \& Cotten, S. R. (2003). The relationship between Internet activities and depressive symptoms in a sample of college freshmen. Cyberpsychology and Behavior, 6(2), 133-142.

Neo, R. L., \& Skoric, M. M. (2009). Problematic instant messaging use. Journal of Computer-Mediated Communication, 14(3), $627-657$.

Niemz, K., Griffiths, M. D., \& Banyard, P. (2005). Prevalence of pathological Internet use among university students and correlations with selfesteem, GHQ and disinhibition. CyberPsychology and Behavior, 8, 562-570.

Norris, M., \& Lecavalier, L. (2009). Evaluating the use of exploratory factor analysis in developmental disability psychological research. Journal of Autism and Developmental Disorders, 40(1), 8-20.

Nunnally, J. C. (1978). Psychometric theory. (2nd Eed.). New York: McGraw Hill.

Potgieter, F. (2014). The mass market engages with mobile: marketing mobile association. [Online] Available: www.bizcommunity. com/Print.aspx?|=196\&c=11\&ct=1\&ci=107704 (Accessed 12 June 2014).

Quan-Haase, A. (2008). Instant messaging on campus: use and integration in university students' everyday communication. The Information Society, 24, 105-115.

Radicati, S. (2013). Instant messaging market report, 2013-2017 developed by the Radicati market research firm. [Online] Available: http://www.radicati.com/wp/wp-content/uploads/2013/09/Instant-Messaging-Market-2013-2017-Executive-Summary.pdf

Ray, C.M., Sormunen, C., \& Harris, T. M. (1999). Men's and women's attitudes toward computer technology: a comparison. Information, Technology, Learning and Performance Journal, 17(1), 1-8.

Rubin, A. M. (2002). The uses-and-gratifications perspectives of media effects. In J. Bryant, \& D. Zillmann (Eds.), Media effects: advances in theory and research, (2nd Ed.). Mahwah, NJ: Lawrence Erlbaum.

Sánchez-Carbonell X., Beranuy M., Castellana M., Chamarro A., \& Oberst U. (2008). Addiction to Internet and cell phone: passing fad or disorder? Adicciones, 20(2), 149-59.

Schwarz, O. (2011). Who moved my conversation? Instant messaging, intertextuality and new regimes of intimacy and truth. Media, Culture and Society, 33(1), 71-87.

Shambare, R., Rugimbana, R., \& Zhowa, T. (2012). Are mobile phones the 21st century addiction? African Journal of Business Management, $6(2), 573-577$.

Swanepoel, T., \& Thomas, K. G. F. (2012). Malicious MXit? South African adolescents' use of mobile-based communication applications. Journal of Child and Adolescent Mental Health, 12(2), 117-132.

Woo, H. J. (2007). A study on the influence of mobile phone users' self-traits on mobile phone addiction. Korean Association for Broadcasting and Telecommunication studies, 21(1), 391-427.

Young, K. S. (1996). Psychology of computer use: XL. Addictive use of the internet: a case study that breaks the stereotype. Psychological Reports, 79(1), 899-902.

Young, K. S. (1998). Internet addiction: the emergency of a new clinical disorder. CyberPsychology and Behaviour, 1(3), $237-244$.

Young, K. S. (2004). Internet addiction: a new clinical phenomenon and its consequences. American Behavioral Scientist, 48(4), $402-415$.

Zikmund, W. G., \& Babin, B. J. (2007). Exploring marketing research. (9th Ed.). USA: Thomson South-Western Publishers.

Zulkefly, S.N., \& Baharudin, R. (2009). Mobile phone use amongst students in a university in Malaysia: its correlates and relationship to psychological health. European Journal of Science Research, 2(1), 206-218. 